\title{
Avaliação quantitativa das dimensões óculo-palpebrais em portadores de cavidade anof tálmica em uso de prótese ocular externa
}

\author{
Quantitative eyelid evaluation of anophthalmic cavity carriers with external \\ ocularprosthesis
}

\author{
RodrigoUeno Takahagi' ${ }^{1}$ \\ Fernando Gonçalves ${ }^{2}$ \\ Silvana Artioli Schellini ${ }^{3}$ \\ Carlos Roberto Padovani ${ }^{4}$ \\ Carlos Roberto Pereira Padovani ${ }^{5}$
}

\begin{tabular}{|l|}
\hline RESUMO \\
\hline Objetivos: Avaliar o posicionamento palpebral em portadores de cavidade \\
anoftálmica com e sem prótese ocular externa, utilizando o processamento \\
de imagem digital. Métodos: Dezoito pacientes foram avaliados qualitativa \\
e quantitativamente na Faculdade de Medicina de Botucatu - Universidade \\
Estadual Paulista - UNESP, com e sem a prótese externa. Usando imagens \\
obtidas por filmadora e processadas usando o programa Scion Image, \\
mediu-se a altura do sulco palpebral superior, a altura da fenda palpebral \\
e os ângulos palpebrais dos cantos interno e externo. Resultados: Pseudo- \\
estrabismo e sulco palpebral superior profundo foram as alterações mais \\
freqüentes ao exame externo. Houve diferença significativa em todas as \\
variáveis estudadas, com diminuição da altura do sulco palpebral superior, \\
aumento da área da fenda palpebral e aumento dos ângulos palpebrais \\
interno e externo quando o paciente estava usando a prótese externa. \\
Conclusão: Todos os pacientes avaliados apresentaram algum tipo de \\
anormalidade órbito-palpebral, o que reflete a dificuldade em se propor- \\
cionar ao portador de cavidade anoftálmica um aspecto idêntico ao que \\
existe na órbita normal. O processamento de imagens digitais permitiu \\
avaliação objetiva das dimensões óculo-palpebrais, o que poderá contri- \\
buir nas avaliações seqüenciais dos portadores de cavidade anoftálmica.
\end{tabular}

Descritores: Doença de Graves/complicações; Blefaroptose/patologia; Enucleação ocular; Doenças palpebrais/patologia; Orbita/cirurgia; Processamento de imagem assistida por computador/métodos; Próteses e implantes; Síndrome

\section{INTRODUCÃO}

A remoção do bulbo ocular e o conseqüente tratamento da cavidade anoftálmica é um desafio para o oftalmologista, demandando esforços a fim de proporcionar resultado estético satisfatório ao paciente. Após a remoção do bulbo ou de seu conteúdo ocorre déficit do volume orbitário que leva, a despeito do tratamento, à "síndrome da cavidade anoftálmica", caracterizada por enoftalmo, sulco palpebral superior profundo, ptose e frouxidão da pálpebra inferior ${ }^{(1-2)}$.

O posicionamento palpebral nas cavidades anoftálmicas, em geral, é avaliado por medidas qualitativas. No entanto, estudos quantitativos usando processamento de imagem digital, estão sendo desenvolvidos em portadores de doença de Graves e blefaroptose congênita ${ }^{(2)}$ e em indivíduos sem doenças oculares ${ }^{(3)}$. 
Empregando avaliações quantitativas, os portadores de cavidade anoftálmica seriam melhor avaliados e acompanhados. Assim, o objetivo deste estudo foi empregar o processamento de imagens digitais para avaliar o posicionamento palpebral em portadores de cavidade anoftálmica, sem e com o uso da prótese ocular externa.

\section{MÉTODOS}

Dezoito pacientes com cavidade anoftálmica, atendidos no ambulatório de Plástica Ocular da Faculdade de Medicina de Botucatu, foram avaliados qualitativa e quantitativamente sem e com o uso da prótese ocular externa.

A avaliação qualitativa foi feita pelo exame externo, usando lanterna oftalmológica, sendo analisadas as possíveis alterações da posição palpebral como entrópio, ectrópio, pseudoptose, ptose de cílios, posição do sulco palpebral, pseudoestrabismo, tricomegalia e outras eventuais alterações.

$\mathrm{O}$ exame quantitativo foi feito analisando-se as imagens obtidas com câmera Sony Digital 8 DCR - TRV110, sob iluminação artificial, com o indivíduo em posição primária do olhar. As imagens obtidas foram processadas pelo computador MacIntosh 400, utilizando-se o programa Imovie e o programa SCION Image (site: scioncorp.com/patês/scion_image_windows.htm), tendo sido tomadas as seguintes medidas:

- altura do sulco palpebral superior: distância da margem da pálpebra superior ao sulco palpebral superior, na região central da fenda palpebral (Figura 1).

- altura da fenda palpebral: medida entre a margem palpebral superior e a margem palpebral inferior, na região central da fenda palpebral (Figura 1).

- ângulo palpebral interno: ângulo formado entre o canto interno (vértice) até a região central das margens palpebrais superior e inferior (Figura 2).

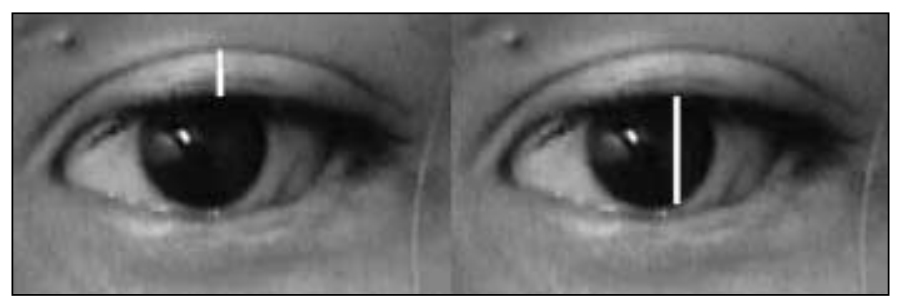

Figura 1 - Representação da medida de altura do sulco palpebral (esquerda) e altura da fenda palpebral (direita) em portador de prótese externa

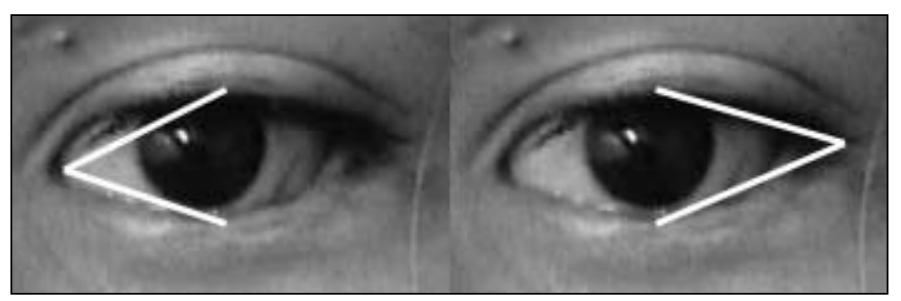

Figura 2 - Representação da medida do ângulo palpebral interno (esquerda) e ângulo palpebral externo (direita) em portador de prótese externa
- ângulo palpebral externo: ângulo formado entre o canto externo (vértice) até a região central das margens palpebrais superior e inferior (Figura 2).

A unidade de medida adotada para a avaliação da altura do sulco e da fenda palpebral foi o diâmetro corneano (dc) do olho contralateral.

Todas as medidas foram feitas antes e após a colocação da prótese externa.

Os dados foram submetidos à avaliação estatística teste $\mathrm{T}$ Student para amostras dependentes ${ }^{(4)}$.

\section{RESULTADOS}

A avaliação qualitativa revelou pseudo-estrabismo em maior proporção $(66,66 \%)$, seguido de sulco palpebral superior profundo $(44,44 \%)$, pseudoptose $(22,22 \%)$, tricomegalia e ectrópio (11,11\% cada), além de entrópio e retração da pálpebra superior (5,55\% ambos) (Tabela 1$)$.

As avaliações quantitativas e respectivos resultados estatísticos estão apresentadas na tabela 2. A altura do sulco palpebral superior sem o uso da prótese foi em média de $0,54 \pm$ 0,24 diâmetro corneano $(\mathrm{dc})$ e com a prótese, de $0,42 \pm 0,21 \mathrm{dc}$, com diferença estatística significativa. A altura da fenda palpebral teve valores médios de $0,54 \pm 0,16 \mathrm{dc}$ sem a prótese externa e $0,83 \pm 0,18 \mathrm{dc}$ com o uso da prótese, com diferença estatística significativa. Com relação ao ângulo externo, sem a prótese, a média foi de $32,75^{\circ} \pm 11,58^{\circ}$ e com a prótese, de $47,03^{\circ} \pm 9,80^{\circ}$, com diferença estatística significativa. Avaliando-se o ângulo interno, as médias foram de $26,21^{\circ} \pm 8,57^{\circ}$, sem a prótese, e de $37,18^{\circ} \pm 6,86^{\circ}$, com a prótese, com diferença estatística significativa.

\section{DISCUSS ÃO}

É muito difícil o portador de cavidade anoftálmica apresentar-se com aspecto idêntico ao lado contralateral, existindo grande chance de se encontrar alguma anormalidade, mesmo que pequena, quando a cavidade anoftálmica é comparada com a órbita normal. Assim, constatou-se que todos os 18 pacientes apresentavam, já ao exame externo, algum tipo de anormalidade órbito-palpebral. A alteração mais comum foi o

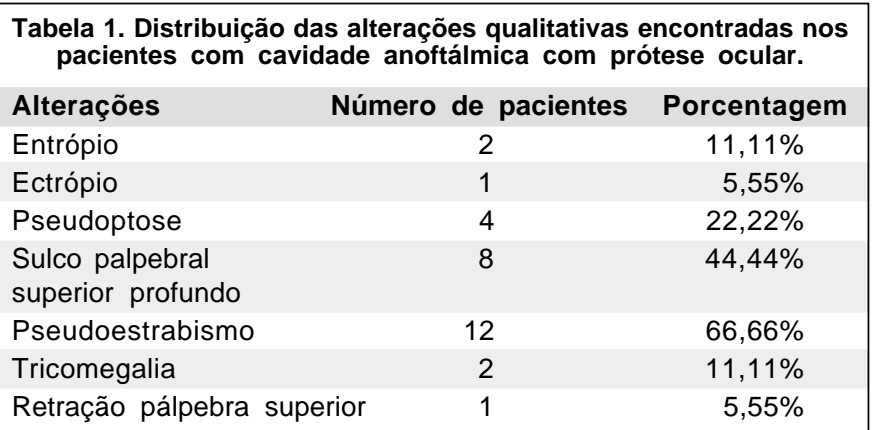




\begin{tabular}{|c|c|c|c|}
\hline \multirow[t]{2}{*}{ Variável } & \multicolumn{2}{|c|}{ Prótese externa } & \multirow{2}{*}{$\begin{array}{l}\text { Resultado do } \\
\text { teste estatístico }\end{array}$} \\
\hline & Sem prótese & Com prótese & \\
\hline Altura do sulco & $0,54 \pm 0,24$ & $0,42 \pm 0,21$ & $3,25(p<0,01)$ \\
\hline Altura da fenda & $0,54 \pm 0,16$ & $0,83 \pm 0,18$ & $6,24(p<0,001)$ \\
\hline Ângulo externo & $32,75^{\circ} \pm 11,58^{\circ}$ & $47,03^{\circ} \pm 9,80^{\circ}$ & $4,41 \quad(p<0,005)$ \\
\hline Ângulo interno & $26,21^{\circ} \pm 8,57^{\circ}$ & $37,18^{\circ} \pm 6,86^{\circ}$ & $6,29(p<0,001)$ \\
\hline
\end{tabular}

pseudoestrabismo, provavelmente em decorrência da movimentação deficiente das próteses externas.

Digitalizar uma imagem significa atribuir valores espaciais (x;y) e de luminância aos pontos (pixels) que compõe a figura. Uma vez digitalizada, a imagem pode ser processada por programas específicos que, ao manipularem matematicamente os pixels, permitem delinear as bordas, filtrar determinadas características e a mensuração de qualquer parâmetro, linear ou curvo, da mesma ${ }^{(5-6)}$.

O uso do processamento digital de imagens, possibilita a análise detalhada de parâmetros oculoplásticos de relevância clínico-cirúrgica. Dentre eles, a mensuração de alguns aspectos palpebrais como os ângulos, a altura do sulco e a abertura da fenda, todos realizados neste estudo.

Para a realização de análise quantitativa de imagens, é muito importante que se adote uma sistemática que impeça a introdução de erros metodológicos. Citando um exemplo, um fator de erro seria a não manutenção da distância entre o objeto de estudo e o sistema de captação de imagens, uma vez que pode haver aumento de tamanho quando se aproxima ou diminuição quando se afasta o objeto da máquina fotográfica ou da filmadora.

O posicionamento do paciente em mentoneiras e manutenção da filmadora em pedestal fixo, poderia ser uma solução. A outra e que foi utilizada neste estudo, foi ter como medida padrão alguma coisa que faz parte de todas as imagens, tendo sido escolhido o diâmetro corneano como unidade de medida. A desvantagem da adoção deste sistema é que não se tem uma medida direta, em milímetros, do fenômeno avaliado, apesar de ser possível a transformação.

Foram observados valores médios do ângulo interno sempre menores que os do ângulo externo, com e sem a prótese. Essas medidas contradizem o formato anatômico de olhos normais, nos quais o ângulo do canto palpebral lateral é normalmente mais agudo que o do canto medial, que é ligeiramente arredondado $^{(6)}$.

Em relação à diferença da medida dos ângulos palpebrais com e sem a prótese, houve aumento estatisticamente significativo dos mesmos após a colocação da prótese externa, o que permitiu aspecto mais semelhante às medidas obtidas em indivíduos normais ${ }^{(3)}$.

A altura do sulco palpebral superior apresentou-se menor nos indivíduos com a prótese ocular, com diferença estatística significativa. É consenso na literatura que a cavidade anoftálmica sem implante orbitário freqüentemente tem maior profun- didade do sulco palpebral superior, um dos sinais da "síndrome da cavidade anoftálmica"(7).

A altura da fenda palpebral mostrou aumento estatisticamente significativo com o uso da prótese ocular, evidenciando que, quando existe volume orbitário maior, a abertura palpebral ocorre mais a contento.

Observou-se ainda que houve aumento da altura da fenda palpebral e diminuição da altura do sulco.

As alterações da órbita e das pálpebras podem ser justificadas pela deficiência de volume na cavidade anoftálmica, decorrente da diminuição de fluxo sangüíneo para os componentes orbitários restantes, com conseqüente atrofia da musculatura extrínseca e da gordura orbitária e pela mobilização das estruturas, por contratura muscular e pela força da gravidade, restando o conteúdo no setor posterior e inferior da órbita. Em consequiência, os tendões e as fáscias também alteram seu posicionamento ${ }^{(7)}$. Assim, na síndrome da cavidade anoftálmica, trabalha-se com mudanças importantes no posicionamento das estruturas. A adaptação da prótese externa pode minimizar estas alterações, mas dificilmente vai sanálas em sua totalidade.

A manutenção dos fórnices conjuntivais adequadamente amplos, a fim de comportar sem resistência a prótese externa, assim como a reposição de volume semelhante ao que existe em órbitas normais, proporciona aspecto estético mais aceitável.

A estreita relação com o protético também é importante para que os resultados possam ser mais satisfatórios.

Além disso, a utilização das avaliações quantitativas pode permitir o diagnóstico e o acompanhamento mais objetivo dos pacientes.

\section{CONCLUSÃO}

A avaliação quantitativa das dimensões óculo-palpebrais nos portadores de cavidade anoftálmica, sem e com o uso da prótese externa diferem estatisticamente. Este tipo de avaliação pode ser útil para as avaliações seqüenciais e acompanhamento dos pacientes.

\section{AgRADECIMENTO}

Os autores agradecem ao Dr. Antonio Augusto Velasco e Cruz que forneceu a base para o desenvolvimento deste estudo. 


\section{ABSTRACT}

Purpose: The authors intend to evaluate the eyelid position before and after the external prosthesis adaptation, using digital image processing techniques. Methods: Eighteen patients were evaluated at the "Faculdade de Medicina de Botucatu Universidade Estadual Paulista - UNESP", with and without the external prosthesis. Qualitative and quantitative analysis were done using the Scion Image program. The superior eyelid sulcus distance, margin eyelid distance and eyelid medial and lateral canthus angles were evaluated. Results: Pseudostrabismus and high eyelid sulcus were the most observed alteration. The superior eyelid sulcus distance had shorter values with the prosthesis and higher values were seen analyzing the other parameters when the external prosthesis was in place. Conclusion: All patients had some abnormalities, which show us how difficult it is to provide a normal aspect for anophthalmic cavity carriers. The image processing allowed objective evaluations of the measures contributing to the follow-up of the patients.
Keywords: Graves' disease/complications; Blepharoptosis/pathology; Eye Enucleation; Eyelid diseases/pathology; Orbit/ surgery; Image processing, computer-assisted/methods; Prostheses and implants; Syndrome

\section{REFERÊNCIAS}

1. Collin JRO. A Manual of systematic eyelid surgery. London: Churchill Livingstone; 1983.

2. Cruz AA, Coelho RP, Baccega A, Lucchezi MC, Souza AD, Ruiz EE. Digital image processing measurement of the upper eyelid contour in Graves's disease and congenital blepharoptosis. Ophthalmology. 1998;105(5):913-8.

3. Sampaio AA, Hoyama E, Schellini SA, Cruz AAV, Padovani CR. Análise computadorizada da porção lateral da fenda palpebral e do posicionamento dos cílios palpebrais superiores. Arq Bras Oftalmol. 2005;68(1):85-8.

4. Norman GR, Streiner DL. Bioestatistics - the base essentials. St. Louis Mosby; 1994.

5. Souza AD, Ruiz EE, Cruz AA. Palpebral fissure morphology segmentation and measurement using image processing. IEEE Eng Med Biol Mag. 2000;19(1): 114-9.

6. Cruz AA, Baccega A. Análise bidimensional computadorizada da fenda palpebral. Arq Bras Oftalmol. 2001;64(1):13-9.

7. Edward H, Bedrossian JR. Embryology and anatomy of the eyelid. In: Tasman W, Jaeger E, editors. Duane's clinical ophthalmology [monography on CDROM]. Philadelphia: Lippincott; 1999.

8. Steinkogler FJ. The Treatment of the post-enucleation socket syndrome. J Craniomaxillofac Surg. 1987;15(1):31-3.

\section{ATUALIZAÇÃO EM OFTALMOLOGIA}

\section{5 de novembro de 2005 \\ Instituto CEMA \\ SÃO PAULO - SP}

IN FO RMAÇÕ ES: Tel: (11) 6602-4034

E-mail: centrodeestudos@cemahospital.com.br 